\title{
Chronic respiratory failure in COPD: is there a place for a respiratory stimulant?
}

The last decade has seen renewed interest in the use of respiratory stimulant drugs to alleviate the effects of chronic hypoxaemia in patients with chronic obstructive pulmonary disease (COPD). Factors behind this interest include the development of respiratory stimulants suitable for long term oral use, ${ }^{1}$ awareness of the potential detrimental effects of nocturnal hypoxaemia, ${ }^{2}$ the reluctance of some patients to consider treatment with long term domiciliary oxygen therapy (LTOT), and practical problems associated with oxygen therapy. LTOT can produce worthwhile improvements in survival in patients with COPD who have chronic ventilatory failure, ${ }^{34}$ but other benefit has been difficult to show. LTOT corrects hypoxia but not hypercapnia, is both expensive and restrictive, requiring great commitment from both patient and family, and so far no definite beneficial effect on quality of life has been shown. ${ }^{5}$ After eight to nine years any survival benefit tails off as a result of progression of airflow obstruction. ${ }^{6}$ Treating chronic respiratory failure with an oral preparation rather than LTOT would be attractive because of its cheapness and convenience, and could be started at a much earlier stage without imposing any restriction on lifestyle. A respiratory stimulant might also be a useful adjunct to LTOT, particularly in those patients who fail to achieve a satisfactory arterial oxygen tension $\left(\mathrm{PaO}_{2}\right)$ without worsening hypercapnia.

The rationale behind giving long term respiratory stimulants to patients with COPD is, however, questionable. In patients with COPD with chronic stable ventilatory failure central respiratory drive is increased, ${ }^{7-9}$ although it is unclear whether this high central respiratory activity is sufficient in the face of increased work of breathing from high airways resistance, hyperinflation with the inspiratory muscles operating close to their fatiguing threshold, and marked disturbances of ventilation and perfusion matching within the lung. Attempting to raise inspiratory effort further pharmacologically may allow an increase in minute ventilation only at the expense of an increase in the oxygen cost of breathing, increased carbon dioxide production by the respiratory muscles, enhanced respiratory muscle fatigue, and worsening dyspnoea.

Many drugs are capable of stimulating ventilation but most are unsuitable for clinical use because of toxic effects. Analeptics such as doxapram which cause generalised stimulation of the central nervous system have a limited role in the treatment of acute exacerbations of ventilatory failure in patients with COPD, but their use is being replaced by ventilatory support. Progestational hormones, carbonic anhydrase inhibitors, methylxanthines, tricyclic antidepressants, and almitrine bismesylate have all been advocated as treatments for chronic respiratory failure in COPD. It may be that some of these drugs, particularly agents such as almitrine bismesylate which has additional effects on modifying breathing pattern and ventilation perfusion matching, now have a place in therapeutic management. What is the current evidence to support their use?

\section{Progestational hormones}

The association between high levels of endogenous progesterone in pregnancy and the latter half of the menstrual cycle and increasing ventilation has long been recognised.
The oral synthetic derivative medroxyprogesterone acetate has similarly been shown to stimulate breathing in normal individuals ${ }^{10}$ and in patients with respiratory disorders. It is probable that progesterone has a central action, crossing the blood-brain barrier to stimulate brain stem respiratory centres to increase alveolar ventilation, ${ }^{11}$ an effect that persists during sleep. ${ }^{1213}$ Medroxyprogesterone increases minute ventilation and the ventilatory responses to both hypoxia and hypercapnia. ${ }^{10}$ It has been used to treat patients with primary alveolar hypoventilation and those with the obstructive sleep apnoea syndrome, although results are disappointing. ${ }^{14}$

In 17 patients with COPD with stable chronic ventilatory failure (mean $\mathrm{FEV}_{1} 1.21, \mathrm{PaO}_{2} 6.6 \mathrm{kPa}, \mathrm{PaCO}_{2} 6.9$ $\mathrm{kPa}) 20 \mathrm{mg}$ medroxyprogesterone acetate three times a day for four weeks caused a significant reduction in mean $\mathrm{PaCO}_{2}$ of $1 \mathrm{kPa}$ and a rise in $\mathrm{PaO}_{2}$ of $0.7 \mathrm{kPa}$ in 10 of the 17 patients. ${ }^{15}$ This was associated with an increase in mouth occlusion pressure, tidal volume, and alveolar ventilation. Those patients who responded could be predicted by their ability to lower arterial carbon dioxide voluntarily while awake. These findings were confirmed by Delaunois et al who found that $75 \mathrm{mg}$ daily of medroxyprogesterone acetate for seven days increased $\mathrm{PaO}_{2}$ and decreased $\mathrm{PaCO}_{2}$ by about $1.0 \mathrm{kPa}$ in nine of 15 stable hypercapnic patients with COPD. ${ }^{16}$ In a similar study $60 \mathrm{mg}$ daily of medroxyprogesterone for one month had no effect on nocturnal oxygen desaturation in 19 patients with COPD despite a mean improvement in daytime $\mathrm{PaO}_{2}$ and a fall in $\mathrm{PaCO}_{2}$ of $0.9 \mathrm{kPa} .{ }^{13}$ Although in a further study Skatrud and colleagues reported less carbon dioxide retention and raised arterial $\mathrm{PaO}_{2}$ in five patients with COPD after four weeks of medroxyprogesterone, the reduction in $\mathrm{PaCO}_{2}$ persisted during sleep. ${ }^{12}$ Medroxyprogesterone has no effect on sleep architecture but in one study the number of arousals increased. ${ }^{1}$ Side effects with medroxyprogesterone are troublesome and include weight gain, gastrointestinal disturbance, anxiety, and there is a theoretical risk of thromboembolic events and exacerbation of hypertension and heart failure. About $10 \%$ of male patients experience loss of libido and impotence.

\section{Carbonic anhydrase inhibitors}

Acetazolamide and the longer acting dichlorphenamide are reversible inhibitors of the enzyme carbonic anhydrase. They have complex actions on cerebral blood flow and cerebrospinal fluid dynamics, but their ventilatory stimulant action probably arises from inhibition of renal tubular hydrogen ion excretion with increased urinary bicarbonate excretion producing a metabolic acidosis which, in turn, stimulates both peripheral and medullary chemoreceptors. ${ }^{9}$ Acetazolamide causes an increase in tidal volume and a parallel shift to the left of the ventilatory response to hypercapnia. ${ }^{917}$ Producing a metabolic acidosis may have theoretical advantages in shifting the oxygen dissociation curve to the right to increase tissue oxygen delivery, but could be dangerous in acute exacerbations of ventilatory failure.

Clinical trials with carbonic anhydrase inhibitors have given disappointing results. Acetazolamide given in a dose of $250 \mathrm{mg}$ twice daily for 10 days improved blood 
gas tensions in only six of 15 patients with COPD with chronic stable carbon dioxide retention, despite an increase in plasma and cerebrospinal fluid hydrogen ion concentration. ${ }^{9}$ In those who did respond $\mathrm{PaO}_{2}$ increased from a mean of 6.8 to $8.5 \mathrm{kPa}$ and $\mathrm{PaCO}_{2}$ fell from 6.8 to $5.4 \mathrm{kPa}$. These patients, however, had less severe airflow obstruction and in this comparative study acetazolamide was a less effective ventilatory stimulant than medroxyprogesterone acetate. Any ventilatory stimulant effect produced by carbonic anhydrase inhibitors is short lived and early studies showed that side effects of headache, depression, paraesthesiae, hypokalaemia, and gastrointestinal upset outweighed any benefit produced. ${ }^{18} 19$ Long term treatment with acetazolamide is also not recommended because of the risk of agranulocytosis which needs monitoring with regular blood counts.

\section{Theophyllines}

Although aminophylline has been used for many years as a respiratory stimulant to treat Cheyne-Stokes respiration,,$^{20}$ the effects of theophyllines on ventilation are controversial. Acute administration of intravenous aminophylline has been shown to increase minute ventilation and the hypoxic ventilatory response without changing the hypercapnic ventilatory response in normal subjects. ${ }^{21}$ Sanders et al found an increase in resting minute ventilation after intravenous aminophylline but no change in the slopes of the hypercapnic and hypoxic ventilatory responses when measured at resting $\mathrm{PaCO}_{2}$ levels. ${ }^{22}$ Two recent studies have shown that oral theophylline, in a dose sufficient to attain therapeutic plasma levels and cause unpleasant side effects, had no effect on hypoxic or hypercapnic ventilatory responses, pulmonary function, or respiratory muscle strength in normal subjects. ${ }^{23}{ }^{24}$ Resting ventilation was increased in one study ${ }^{23}$ but was unchanged in the other. ${ }^{24}$ It is thought that any increase in ventilation produced by theophyllines occurs secondary to inhibition of central neurotransmitters, such as adenosine, which tonically inhibit ventilation. ${ }^{25}$ Any respiratory stimulant effect is not prolonged, however, and long term treatment of COPD patients with oral theophyllines brings about only minor, if any, improvement in gas exchange. ${ }^{26}$ Both intravenous aminophylline and oral theophylline have no effect on improving overnight oxygenation in patients with COPD. ${ }^{27}{ }^{28}$ The rationale for prescribing theophyllines to patients with COPD is primarily for their bronchodilator action, but even then their use is controversial. ${ }^{29}{ }^{30}$ Caution must be exercised when using theophyllines as increasing age, smoking, hypoxia, and hepatic congestion will all delay drug clearance and predispose to toxicity. ${ }^{31}$

\section{Tricyclic antidepressants}

Protriptyline, a non-sedating tricyclic antidepressant, decreases time spent in rapid eye movement (REM) sleep $^{32}$ when most severe falls in nocturnal oxygen saturation $\left(\mathrm{SaO}_{2}\right)$ occur. $^{2}$ It may also preferentially increase activity in the pharyngeal muscles during sleep to reduce upper airway resistance. ${ }^{33}$ Protriptyline has no stimulatory effect on ventilation during wakefulness. ${ }^{34}$ In 16 stable patients with COPD (mean $\mathrm{FEV}_{1} 1.01, \mathrm{PaO}_{2} 7 \cdot 8$ $\left.\mathrm{kPa}, \mathrm{PaCO}_{2} 6.5 \mathrm{kPa}\right) 20 \mathrm{mg}$ protriptyline at night for 10 weeks increased $\mathrm{PaO}_{2}$ by a mean of $0.9 \mathrm{kPa}$ and decreased $\mathrm{PaCO}_{2}$ by $0.3 \mathrm{kPa}$ compared with a two week run in placebo period. ${ }^{35}$ Sleep architecture did not alter apart from the expected decrease in REM sleep time with an associated improvement in nocturnal oxygen desaturation. Eleven of the 16 patients reported a subjective improvement in sleep quality. In a double blind placebo controlled crossover trial $10 \mathrm{mg}$ of protriptyline at night for six weeks decreased total REM sleep time from $16 \%$ to $9 \%$ and produced a small improvement in total sleep time spent with an $\mathrm{SaO}_{2}$ below $90 \%$ in 17 patients with more severe airflow obstruction and hypoxia (median $\left.\mathrm{FEV}_{1} 0.6 \mathrm{l}, \mathrm{PaO}_{2} 6.9 \mathrm{kPa}, \mathrm{PaCO}_{2} 6.4 \mathrm{kPa}\right){ }^{36}$ This was associated with a fall in daytime $\mathrm{PaCO}_{2}$ of about $1 \mathrm{kPa}$, a small but non-significant rise in daytime $\mathrm{PaO}_{2}$, and a small increase in maximal inspiratory pressure and six minute walking distance. Measures of breathlessness were unchanged, although an improvement in well being (assessed by the General Health Questionnaire) was recorded, presumably because of the antidepressant properties of protriptyline. Unfortunately dose dependent anticholinergic side effects such as dry mouth, urinary retention, blurred vision, and constipation are common with protriptyline; in the study by Carroll et al ${ }^{36}$ all 17 patients noted side effects and five said they would be reluctant to continue treatment on a long term basis.

\section{Almitrine bismesylate}

Almitrine bismesylate is a piperazine derivative which is well absorbed orally but has a long half life of several weeks. It differs importantly from other respiratory stimulants in that it increases ventilation through a stimulatory action on the carotid and aortic body chemoreceptors $^{37}$ with no effect on the central nervous system. Almitrine improves arterial blood gas tensions in patients with COPD but its mode of action is uncertain and probably involves several mechanisms. Minute ventilation increases but improvement in blood gas tensions is often greater than would be expected from the observed increase in ventilation..$^{38} 39$ Other mechanisms include an alteration in breathing pattern causing subtle changes in alveolar ventilation, ${ }^{40}$ and a direct vasoconstrictor action on small pulmonary blood vessels redistributing blood flow to areas with better ventilation. ${ }^{39} 4142$

Several studies have examined the effect of almitrine bismesylate in hypoxic patients with COPD for periods of up to a year. The largest of these, the Vectarion International Multicentre Study (VIMS), examined the effect of 50-100 mg almitrine twice daily, the dose being titrated against initial improvement in $\mathrm{PaO}_{2}$, or placebo in 701 patients with stable hypoxic COPD (mean FEV $\left.0.871, \mathrm{PaO}_{2} 7.6 \mathrm{kPa}, \mathrm{PaCO}_{2} 6.0 \mathrm{kPa}\right){ }^{43}$ After 12 months of treatment $\mathrm{PaO}_{2}$ had increased in the actively treated patients by about $1 \mathrm{kPa}$ with a third achieving a rise of 2 $\mathrm{kPa}$; mean $\mathrm{PaO}_{2}$ in the almitrine treated group at 12 months was $8.5 \mathrm{kPa}$. The corresponding fall in $\mathrm{PaCO}_{2}$ was much smaller but was still significant with a mean $\mathrm{PaCO}_{2}$ at 12 months of $5.7 \mathrm{kPa}$. There were no significant changes in blood gas tensions during the study period in the placebo treated patients. In the group treated with almitrine $25 \%$ did not show any improvement in blood gas tensions, defined as an increase in $\mathrm{PaO}_{2}$ of less than $0.7 \mathrm{kPa}$. It was not possible to predict "good responders" from "non-responders" from baseline physiological and clinical measurements, although "good responders" tended to have less severe disease and be less hypercapnic. The almitrine treated group experienced a reduction in secondary polycythaemia, a decrease in the number of hospital admissions, a small but significant improvement in $\mathrm{FEV}_{1}$, but no change in six minute walking distance. Quality of life was not assessed. Unfortunately the improvement in blood gas tensions was achieved at the expense of a large number of drug side effects, namely increased dyspnoea, gastrointestinal disturbance, malaise, weight loss, and peripheral neuropathy. In total $40 \%$ of 
the actively treated group withdrew from the study compared with $25 \%$ of the controls. Side effects correlated with drug plasma levels, which were often well above the therapeutic range of $200-300 \mathrm{ng} / \mathrm{ml}$ due to the unexpectedly long half life.

Eighty nine patients from the VIMS study continued treatment for two years with significant improvement in blood gas tensions being maintained. ${ }^{44}$ Again withdrawals were high with 29 of 43 almitrine treated and 22 of 46 placebo treated patients failing to complete the full two years of treatment. No difference was seen in survival between the placebo and almitrine treated groups. Survival at two years was $82 \%$ in the actively treated patients and $86 \%$ in those taking placebo. Survival after two years was better than that observed in the treated groups in the NOTT and MRC LTOT trials where rates were $78 \%$ and $77 \%$ respectively. ${ }^{34}$ Patients in the almitrine study were, however, less hypoxic, and not all were hypercapnic or had experienced episodes of oedema. To determine any beneficial effect on survival patients with more severe arterial hypoxia need to be studied for longer periods.

Two recent studies, one from Europe and one carried out in several centres in the UK, have examined the effect of a lower dose of almitrine (approximately half the dose used in the VIMS study), 25-50 mg twice daily with an intermittent schedule of administration of two months treatment followed by a one month washout period to allow for the drug's long half life. ${ }^{45} 46$ The UK study ran for 18 months, only the first six of which were double blind and placebo controlled, all patients then taking the active drug for a further six months. ${ }^{45}$ In view of the previous problems with peripheral neuropathy, peripheral nerve function was subject to particular scrutiny with careful clinical and electrophysiological evaluation. Eighty five patients with COPD were studied (mean $\mathrm{FEV}_{1} 0.891, \mathrm{PaO}_{2} 7.8 \mathrm{kPa}, \mathrm{PaCO}_{2} 5.8 \mathrm{kPa}$ ). After six months the improvement in baseline $\mathrm{PaO}_{2}$ values with almitrine was $0 \cdot 8-1 \cdot 3 \mathrm{kPa}$, similar to that found with higher doses in the VIMS study, with again about a third of patients showing no response. $\mathrm{PaCO}_{2}$ fell slightly in the patients taking almitrine but blood gas tensions did not alter in the placebo treated patients. After withdrawal of therapy blood gases slowly reverted to pretreatment levels. The sequential dosing regimen allowed plasma drug levels to stabilise within the therapeutic range and produced fewer side effects, although there was still a high drop out rate of $28 \%$ in the almitrine group and $20 \%$ in the placebo group. Dyspnoea, gastrointestinal disturbances, and paraesthesiae were recorded equally between the groups. No increase in six minute walking distance occurred with almitrine. A substantial degree of peripheral nerve dysfunction was found, with only 28 patients (38\%) having a normal electromyographic study before entering the trial. The majority of abnormalities were, however, entrapment neuropathies, most of which were asymptomatic with only three $(5 \%)$ having a possible generalised peripheral neuropathy. During the study period there was a slight reduction in peroneal motor conduction velocity in both the treated and control groups but no patient developed a clinical peripheral neuropathy.

The European study evaluated pulmonary haemodynamic changes during long term almitrine treatment. ${ }^{46}$ There had been uncertainty over the long term safety of almitrine since acute increases in mean pulmonary artery pressure were observed in short term studies after both intravenous and oral administration attributed to enhanced hypoxic vasoconstriction..$^{38} 47$ Weitzenblum and coworkers $^{46}$ treated 45 hypoxic patients with COPD (mean $\mathrm{FEV}_{1} 1.04 \mathrm{l}, \mathrm{PaO}_{2} 7.6 \mathrm{kPa}, \mathrm{PaCO}_{2} 5.8 \mathrm{kPa}$ ) with either low dose intermittent almitrine or placebo for 12 months. In the 16 patients treated with almitrine who completed the study no change in mean pulmonary artery pressure (measured both at rest and during exercise), pulmonary vascular resistance, or cardiac output occurred despite achieving therapeutic almitrine levels and a modest improvement in $\mathrm{PaO}_{2}$ of around $0.8 \mathrm{kPa}$. No changes in blood gas tensions or pulmonary haemodynamics were recorded in 10 placebo treated patients who finished the study.

Almitrine has been shown to improve nocturnal oxygenation in patients with COPD largely by increasing $\mathrm{PaO}_{2}$ when awake and raising the baseline $\mathrm{SaO}_{2}$. In nine patients with COPD in ventilatory failure (mean $\mathrm{FEV}_{1}$ $\left.0.61, \mathrm{PaO}_{2} 6.7 \mathrm{kPa}, \mathrm{PaCO}_{2} 6.5 \mathrm{kPa}\right) 50 \mathrm{mg}$ almitrine twice daily for 14 days improved daytime blood gas tensions and oxygenation during sleep, lowest $\mathrm{SaO}_{2}$ rising from an average $65 \%$ to $77 \%$ without impairing sleep quality. ${ }^{48}$ In six patients $1.5 \mathrm{mg} / \mathrm{kg}$ almitrine was more effective in improving nocturnal oxygen desaturation than $100 \mathrm{mg}$ medroxyprogesterone. ${ }^{1}$ Further studies, although again containing small numbers, have shown the effect of almitrine on nocturnal desturation to be maintained after treatment for up to a year without any changes in the quality or quantity of sleep. ${ }^{49} 50$ There does not, however, appear to be any additional benefit from combining almitrine with oxygen to treat nocturnal oxygen desaturation. ${ }^{51}$ There is evidence from short term studies that, in patients with COPD on LTOT who cannot attain a satisfactory $\mathrm{PaO}_{2}$ without excessive hypercapnia, supplemental almitrine bismesylate may be a useful additional treatment. ${ }^{52}$ There was also evidence of a useful additive effect to LTOT from the VIMS study, although no long term studies have addressed this issue.

\section{Conclusions}

Treatment with respiratory stimulant drugs can produce sustained improvements in both daytime and nocturnal arterial blood gas tensions in some patients with COPD. However, patients in whom arterial blood gas tensions are likely to improve tend to have less severe disease with less mechanical impairment to ventilation. Other benefit has not been realised and side effects with all agents are troublesome. Almitrine bismesylate shows most promise, yet after a decade of investigation no clear place in the therapeutic management for patients with COPD has emerged. There is currently no convincing scientific evidence that any long term respiratory stimulant improves either symptoms or survival in patients with hypoxic COPD. Their use must remain experimental.

P A BARDSLEY Senior Registrar in Respiratory Medicine, Glenfield Hospital, Groby Road, Leicester LE3 9QP

Reprint requests to: Dr PA Bardsley

1 Daskalopoulou E, Patakas D, Tsara V, Zoglopitis F, Maniki E Comparison of almitrine bismesylate and medroxyprogesterone acetate on oxygenation during wakefulness and sleep in patients with chronic obstructive lung disease. Thorax 1990;45:666-9.

2 Douglas NJ, Flenley DC. Breathing during sleep in patients with obstructive lung disease. Am Rev Respir Dis 1990;141:1055-70.

3 Medical Research Council. Domiciliary oxygen trial. Lancet 1981;i:681-5.

4 Noctural Oxygen Therapy Trial (NOTT) Group. Continuous or nocturnal oxygen therapy in hypoxaemic chronic obstructive lung disease. Ann Intern Med 1970;93:394-9.

5 Strom K, Boe J, Boman G, Skoogh BE. Expectations of benefit from long-term oxygen therapy. Eur Respir Rev 1991;1:541-9.

6 Cooper CB, Waterhouse J, Howard P. A 12 year clinical study of patients with hypoxic cor pulmonale given long term domiciliary oxygen therapy. Thorax 1987;42:105-10. 
7 Sorli A, Grassino A, Lorange G, Milic-Emili J. Control of breathing in patients with chronic obstructive lung disease. Clin Sci Mol Med 1978;54:295-304.

8 Aubier M, Murciano D, Fournier M, Milic-Emili J, Pariente R, Derenne JP. Central respiratory drive in acute respiratory failure of patients with chronic obstructive pulmonary disease. Am Rev Respir Dis 1980;122: $191-9$.

9 Skatrud JB, Dempsey JA. Relative effectiveness of acetazolamide and medroxyprogesterone acetate in correction of chronic carbon dioxide retention. Am Rev Respir Dis 1983;127:405-12.

10 Zwillch CW, Natalino MR, Sutton FD, Weil JV. Effects of progesterone on chemosensitivity in normal men. 7 Lab Clin Med 1978;92:262-9.

11 Skatrud JB, Dempsey JA, Kaiser DG. Ventilatory response to medroxyprogesterone acetate in normal subjects: time course and mechanism. f Appl Physiol 1978;44:939-44.

12 Skatrud JB, Dempsey JA, Iber C, Berssenbrugge A. Correction of $\mathrm{CO}_{2}$ retention during sleep in patients with chronic obstructive pulmonary disease. Am Rev Respir Dis 1981;124:260-8.

13 Dolly FR, Block AJ. Medroxyprogesterone acetate and COPD: effect on breathing and oxygenation in sleeping and awake patients. Chest 1983;84:394-7.

14 Millman RP. Medroxyprogesterone and obstructive sleep apnoea. Chest 1989;96:225-6.

15 Skatrud JB, Dempsey JA, Bhansali P, Irvin C. Determinants of chronic carbon dioxide retention and its correction in humans. $f$ Clin Invest 1980;65:813-21.

16 Delaunois L, Delwiche JP, Lulling J. Effect of medroxyprogesterone on ventilatory control and pulmonary gas exchange in chronic obstructive patients. Respiration 1985;47:107-13.

17 Fencl V, Vale JR, Brock JA. Respiration and cerebral blood flow in metabolic acidosis and alkalosis in humans. $\mathcal{F}$ Appl Physiol 1969;27:67-76.

18 Galdston $M$. Respiratory and renal effects of a carbonic anhydrase inhibitor (Diamox) on acid-base balance in normal man and in patients with respiratory acidosis. Am $\mathcal{f}$ Med 1955;19:516-31.

19 Dorris R, Olivia JV, Rodman T. Dichlorphenamide, a potent carbonic anhydrase inhibitor: effect on alveolar ventilation, ventilation-perfusion relationships and diffusion in patients with chronic lung disease. $A m \mathcal{F}$ Med 1964;36:79-86.

20 Dowell AR, Heyman A, Sieker HO, Tripathy K. Effect of aminophylline on respiratory center sensitivity in Cheyne-Stokes respiration and in pulmonary emphysema. N Engl ₹ Med 1965;273:1447-53.

21 Lakshminarayan S, Sahn SA, Weil JV. Effect of aminophylline on ventilatory responses in normal man. Am Rev Respir Dis 1978;117:33-8.

22 Sanders JS, Berman TS, Bartlett MM, Kronenberg RS. Increased hypoxic ventilatory drive to administration of aminophylline in normal men. Chest 1980;78:279-82.

23 Javaheri S, Guerra L. Lung function, hypoxic and hypercapnic ventilatory responses and respiratory muscle strength in normal subjects taking oral theophylline. Thorax 1990;45:743-7.

24 Swaminathan S, Paton JY, Davidson Ward SL, Sargent CW, Keens TG. Theophylline does not increase ventilatory responses to hypercapnia or hypoxia. Am Rev Respir Dis 1992;146:1398-401.

25 Rall TW. Central nervous system stimulants: the methylxanthines. In: Gilman AG, Goodman LD, Rall TW, Murad F, eds. The pharmacological basis of therapeutics. 7th edn. New York: Macmillan, 1985:589-603.

26 Hill NS. The use of theophylline in "irreversible" chronic obstructive pulmonary disease. Arch Intern Med 1988;148:2579-84.

27 Ebden P, Vathenan AS. Does aminophylline improve noctural hypoxia in patients with chronic airflow obstruction? Eur $\mathcal{F}$ Respir Dis 1987;71: 384-7.

28 Martin RJ, Pak J. Overnight theophylline concentrations and effects on sleep and lung function in chronic obstructive pulmonary disease. $A m$ Rev Respir Dis 1992;145:540-4.

29 Johnston ID. Theophylline in the management of airflow obstruction: difficult drugs to use, few clinical indications. $B M F$ 1990;300:929-31.

30 Addis GJ. Theophylline in the management of airflow obstruction: much evidence suggests that theophylline is valuable. BMF 1990;300:928-9.

31 Cochrane GM. Slow release theophyllines and chronic bronchitis. BMf 1984;289:1643-4.

32 Conway WA, Zorick F, Piccione P, Roth T. Protriptyline in the treatment of sleep apnoea. Thorax 1982;37:49-53.
33 Bonora M, John WM, Bledsoe TA. Differential elevation by protriptyline and depression by diazepam of upper airway motor activity. Am Rev Respir Dis 1985;131:41-5.

34 Simonds AK, Carroll N, Branthwaite MA, Saunders NA. Effect of protriptyline on ventilatory responses to hypercapnia and asphyxia in normal subjects. Eur Respir F 1989;2:758-63.

35 Series F, Cormier Y. Effects of protriptyline on diurnal and nocturnal oxygenation in patients with chronic obstructive pulmonary disease. Ann Intern Med 1990;113:507-11.

36 Carroll N, Parker RA, Branthwaite MA. The use of protriptyline for respiratory failure in patients with chronic airflow limitation. Eur Respir $\mathcal{F}$ 1990;3:746-51.

37 Laubie $\mathrm{M}$, Schmitt $\mathrm{H}$. Long lasting hyperventilation induced by almitrine: evidence for a specific effect on carotid and thoracic chemoreceptors Eur $\mathcal{F}$ Pharmacol 1980;61:123-36.

38 Naeije R, Melot C, Mols P, Hallemans R, Naeije N, Cornil A, et al. Effects of almitrine in decompensated chronic respiratory insufficiency. Bull Eur Physiopathol Respir 1981;17:153-61.

39 Powles ACP, Tuxen DV, Mahood B, Pugsley SO, Campbell EJM. The effect of intravenously administered almitrine, a peripheral chemoreceptor agonist, on patients with chronic airflow obstruction. Am Rev Respir Dis 1983;127:284-9.

40 Stradling JR, Nicholl CG, Cover D, Davies EE, Hughes JMB, Pride NB. The effects of oral almitrine on pattern of breathing and gas exchange in patients with chronic obstructive pulmonary disease. Clin Sci 1984 66:435-42.

41 Melot C, Naeije R, Rothschild T, Mertens P, Mols P, Hallemans R. Improvement in ventilation perfusion matching by almitrine in COPD. Chest 1983;83:528-33.

42 Le Merre C, Ansquer JC, Clark MJ, Zouari N, Prefaut C. Is the mode of action of almitrine bismesylate dose dependent? Respiration 1989;56: 212-9.

43 Voisin C, Howard P, Ansquer JC. Almitrine bismesylate: a long-term placebo-controlled double-blind study in COAD. Vectarion International Multicentre Study Group. Bull Eur Physiopathol Respir 1987;23(Suppl 11):169-82.

44 Bardsley PA, Howard P, DeBacker W, Vermeire P, Mairesse M, Leden $\mathrm{C}$, et al. Two years treatment with almitrine bismesylate in patients with hypoxic chronic obstructive airways disease. Eur Respir $f$ 1991;4: 308-10.

45 Bardsley PA, Howard P, Tang O, Empey D, Harrison B, Peake MD, et al Sequential treatment with low dose almitrine bismesylate in hypoxaemic chronic obstructive airways disease. Eur Respir f 1992;5:1054-61.

46 Weitzenblum E, Schrijen F, Apprill M, Prefaut C, Yernault JC. One yea treatment with almitrine improves hypoxaemia but does not increas pulmonary artery pressure in COPD patients. Eur Respir $\mathcal{f} 1991 ; 4$ 1215-22.

47 Macnee W, Connaughton JJ, Rhind GB, Hayhurst MD, Douglas J, Muir $\mathrm{AL}$, et al. A comparison of the effects of almitrine or oxygen breathin on pulmonary arterial pressure and right ventricular ejection fraction in hypoxic chronic bronchitis and emphysema. Am Rev Respir Dis 1986; 134:559-65.

48 Connaughton JJ, Douglas NJ, Morgan AD, Shapiro CM, Critchley JAJH, Pauly N, et al. Almitrine improves oxygenation when both awake and asleep in patients with hypoxia and carbon dioxide caused by chronic bronchitis and emphysema. Am Rev Respir Dis 1985;132:206-10.

49 Gothe B, Cherniack NS, Bachand RT Jr, Szalkowski MB, Bianco KA. Long term effects of almitrine bismesylate on oxygenation during wakefulness and sleep in chronic obstructive pulmonary disease. $A m \mathcal{F} M e$ 1988;84:436-44.

50 Racineux JL, Meslier N, Hubert P. The effect of long-term almitrine ther apy on sleep hypoxaemia in patients with chronic airways obstruction. Bull Eur Physiopathol Respir 1987;23(Suppl 11):183-4.

51 Ruhle KH, Kempf P, Mösinger B, Klein G, Costabel U, Würtenberger G, et al. Einfluss von almitrin einem chemorezeptoren stimulator, auf die nächtliche hyperkapnie und den pulmonarteriellen Druk unter $\mathrm{O}_{2}$ Atmung bei chronisch obstruktiver lungenerkrankung. Prax Clin Pneumonol 1988;42:411-4.

52 Evans TW, Tweney J, Waterhouse JC, Nichol J, Suggett AJ, Howard P. Almitrine bismesylate and oxygen therapy in hypoxic cor pulmonale. Thorax 1990;45:16-21. 